\title{
Chest HRCT findings in patients with primary Sjögren's syndrome
}

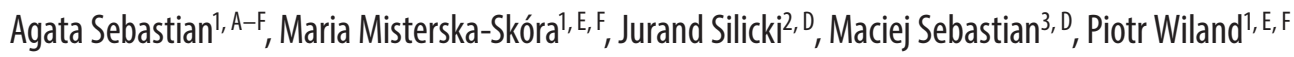 \\ ${ }^{1}$ Department of Rheumatology and Internal Medicine, Wroclaw Medical University, Poland \\ ${ }^{2}$ Department of General and Pediatric Radiology, Wroclaw Medical University, Poland \\ ${ }^{3}$ Department of Minimally Invasive Surgery and Proctology, Wroclaw Medical University, Poland \\ A - research concept and design; $\mathrm{B}$ - collection and/or assembly of data; $\mathrm{C}$ - data analysis and interpretation; \\ $D$ - writing the article; $E$ - critical revision of the article; $F$ - final approval of article
}

\section{Agata Sebastian \\ E-mail: agatasebastian@vp.pl \\ Funding sources \\ None declared \\ Conflict of interest \\ None declared}

Address for correspondence

Received on August 18, 2015

Revised on November 1, 2016

Accepted on February 14, 2017

\begin{abstract}
Background. Pulmonary manifestations (PMs) in primary Sjögren's syndrome (pSS) are among the most frequent extraglandular complications, with reported prevalence varying widely (9-75\%), depending on the methods of detection.
\end{abstract}

Objectives. The aim of this study was to assess the incidence of PMs in pSS and to determine the factors predisposing to the occurrence of this complication.

Material and methods. The study group consisted of 68 patients with pSS. Among the patients who were possibly affected by PMs, chest High Resolution Computed Tomography (HRCT) was performed.

Results. In the group of all patients afflicted with pSS, 30 people indicated the need to expand medical imaging via chest HRCT scan. (The most frequent reason, in 80\% of patients, was persistent, dry cough periodically waking up patients at night). The chest HRCT scan revealed lung tissue changes in the course of $29 \%$ of all examined patients (of 68). No correlation was found between the occurrence of HRCT changes and the age of patients $(p=0.8)$, increased CRP $>5 \mathrm{mg} / 1(p=0.1)$ or ESR $>20 \mathrm{~mm} / \mathrm{h}(p=0.9)$, focus score $(p=0.8)$, leucopenia $(p=0.5)$, RF value $(p=0.3)$, gamma globulin value $(p=0.5)$, intensity of eye and oral cavity dryness $(p=0.6 ; 0.3)$, and smoking cigarettes. Additionally, no correlation was found between more frequent occurrences of antibodies anti-SSA, anti-SSB or anti-Ro52 and HRCT changes $(p=0.3 ; 0.07$; 0.4). Pertaining to the clinical signs, HRCT changes occurred more often only in patients suffering from peripheral arthritis $(p<0.01)$.

Conclusions. PM is a frequent symptom of pSS. A factor predisposing to the development of changes in the respiratory system was not found. Changes in HRCT occur more frequently in patients with peripheral arthritis.

Key words: chest HRCT, primary Sjogren's syndrome, pulmonary manifestation

DOI

10.17219/acem/68978

\section{Copyright}

Copyright by Author(s)

This is an article distributed under the terms of the

Creative Commons Attribution Non-Commercial License

(http://creativecommons.org/licenses/by-nc-nd/4.0/) 
Primary Sjögren's syndrome (pSS) is a chronic autoimmune disease with symptoms occurring in many organs, specifically in the salivary glands, lacrimal glands and musculoskeletal system. Symptoms are often weakly expressed resulting in a mean diagnostic delay of 6-7 years. ${ }^{1}$ Lymphocytic infiltrates characteristic of pSS may be localized in the respiratory tract. The prevalence of respiratory symptoms in pSS varies a lot (9-75\%), depending on the publications and assessment methods (clinical symptoms, chest X-ray, computed tomography). ${ }^{2}$ High Resolution Computed Tomography (HRCT) is a relatively noninvasive method and is currently the most important method for detecting early lung parenchymal abnormalities and reduced lung function. Common HRCT findings of pSS in the lungs include ground-glass attenuation, bronchiectasis, a reticular pattern and honeycomb appearance. ${ }^{3}$ The presence of honeycombing was associated with increased mortality in pSS. There was a fourfold increased risk of dying after 10 years of the disease among patients with lung involvement compared with those without lung involvement in a Norwegian population. ${ }^{4}$

Changes in the respiratory tract in pSS can occur as variable symptoms, which was considered in the EULAR Sjögren's Syndrome Disease Activity Index (ESSDAI). ${ }^{5}$ It consists of the subjective and objective symptoms including persistent dry cough, bronchial involvement, shortness of breath, radiographic abnormalities on radiography or in chest HRCT and abnormal lung function tests $\left(70 \%>\mathrm{DL}_{\mathrm{CO}} \geq 40 \%\right.$ or $\left.80 \%>\mathrm{FVC} \geq 60 \%\right)$. The pulmonary weight has a value of 5 points. A maximum total score of 15 points can be achieved. It is suggested that a score of 5 points is associated with moderate pSS activity and > 14 points with shorter survival. ${ }^{6,7}$

The aim of this study was to assess the incidence of pulmonary manifestations in pSS and to determine factors predisposing to this complication.

\section{Material and methods}

The study group consisted of 68 patients ( 66 women and 2 men) with a diagnosis of pSS on the basis of the American-European criteria of Sjögren's Syndrome Classification from $2002^{8}$, who were treated in the Department of Rheumatology and Internal Medicine, Wroclaw Medical Hospital, in the years 2010-2014. Written informed consent was obtained from each patient before the study. The study was accepted by the Commission of Bioethics at Wroclaw Medical University (no. 357/2010). The median age of patients was 51 (19-82) years. The median time between the onset of first symptoms and diagnosis of pSS was 7.5 years; among patients with changes in the respiratory system, the average time was 7 years and it was the shortest in comparison to other initial symptoms: changes in major salivary glands (10 years), enlarged peripheral lymph nodes (9 years), skin changes (11 years), arthritic changes (9 years). Among the patients who were possibly affected by pulmonary manifestations, chest HRCT was performed without and with administration of contrast medium. Symptoms leading to the expanding of medical imaging by chest HRCT were dry cough not related to the infection and lasting for 3 months, dyspnea, decreasing stamina due to the symptoms of dyspnea or paroxysmal dry cough.

The efficacy of immunosuppressive therapy was assessed on the basis of the chest HRCT performed on patients who have been receiving treatment for more than 6 months (Table 1, patient number 3, 5, 6, 8-11, 13, 15 and 16). The examination was performed with the same equipment. Additionally, all of these patients underwent basic laboratory tests including a complete circumferential blood count, concentration of C-reactive protein (CRP, nv $<5 \mathrm{mg} / \mathrm{L}$ ), erythrocyte sedimentation rate (ESR, $\mathrm{nv}<15 \mathrm{~mm} / \mathrm{h}$ ), value of gamma globulins marked in electrophoresis of proteins (nv 0.6-1.2 g/dL), immunological panel including rheumatoid factor (RF, nv $<14 \mathrm{IU} / \mathrm{mL}$ ) and specific antibodies anti-SSA, anti-SSB and anti-Ro52 (Anti-ENA ProfilePlus1 EUROLINE, EUROIMMUN, Lübeck, Germany) as well as the assessment of lymphoid infiltrates in minor salivary glands graded on the focus score scale (0-4). The assessment of the degree of intensity of symptoms of the oral cavity and eye dryness was based on the EULAR Sjögren's Syndrome Patient Reported Index Scale (ESSPRI). ${ }^{9} 0$ points indicated no symptoms of dryness whereas 10 points indicated strong intensity of dryness which made everyday functioning difficult for patients. In statistical analysis, the Student's t-test, Kruskal-Wallis test and ANOVA were used to compare 3 groups of patients (with positive and without changes in chest HRCT and patients without chest HRCT). The assumed alpha significance level was $0.05, \mathrm{p}<0.05$.

\section{Results}

In the group of all patients with pSS, 30 (44\%, females only) indicated the need to expand medical imaging via chest HRCT scan. The symptoms leading to this examination were as follows: in $80 \%$ of cases it was constant, dry and persistent cough periodically waking up the patients at night. In $18 \%$ of cases it was the decreased stamina mainly due to coughing fits (91\%). In $2 \%$ of cases, dyspnea not related to dry cough was reported. There were no changes in patients undergoing clinical chest examination. No correlation was found between the respiratory system symptoms and cigarette smoking. There were no other factors which were found to have an influence on the changes in the lungs, for example profession, older age and longer duration of pSS. In the group of patients with pSS who did not have a HRCT scan first, chest radiography was obtained, which were positive in all but 2 cases (a lung tumor and suspicion of in- 
Table 1. Treatment of patients with changes in the chest HRCT

\begin{tabular}{|c|c|c|c|c|c|c|c|}
\hline $\begin{array}{l}\text { Patient } \\
\text { No. }\end{array}$ & $\begin{array}{c}\text { Treatment } \\
\text { duration (months) }\end{array}$ & $\begin{array}{l}\text { Treatment before } \\
\text { chest HRCT }\end{array}$ & $\begin{array}{l}\text { Efficacy of treatment } \\
\text { (control chest HRCT) }\end{array}$ & $\begin{array}{l}\text { Encorton } \\
\text { (mg) }\end{array}$ & $\begin{array}{l}\text { Cyclosporine } \\
\text { (mg) }\end{array}$ & $\begin{array}{l}\text { Azathioprine } \\
\text { (mg) }\end{array}$ & $\begin{array}{l}\text { Type of changes } \\
\text { (chest HRCT) }\end{array}$ \\
\hline 1 & $<6$ & $\mathrm{HQ}$ & - & - & - & 150 & $N / F$ \\
\hline 2 & $<6$ & HQ,GKS & - & 10 & - & - & $M L$ \\
\hline 3 & 12 & $\mathrm{HQ}, \mathrm{CYC}$ & stabile & 2.5 & 150 & - & N \\
\hline 4 & $<6$ & $\mathrm{CHQ}, \mathrm{CYC}, \mathrm{GKS}$ & - & 10 & - & 150 & $\mathrm{~N} / \mathrm{ML}$ \\
\hline 5 & 6 & CHQ,GKS & complete regression & 7.5 & 150 & - & $\mathrm{GGO} / \mathrm{ML}$ \\
\hline 6 & 9 & $n$ dgn & stabile & 5 & 150 & - & N \\
\hline 7 & $<6$ & $\mathrm{HQ}, \mathrm{AZA}$, & - & - & - & 175 & F \\
\hline 8 & 15 & CHQ, GKS & stabile & 10 & - & 100 & $\mathrm{~F} / \mathrm{ML}$ \\
\hline 9 & 12 & ndgn & progression & 10 & - & 150 & GGO \\
\hline 10 & 13 & ndgn & complete regression & 5 & - & 150 & $\mathrm{~F} / \mathrm{ML}$ \\
\hline 11 & 13 & CYC & - & 2.5 & - & 100 & GGO \\
\hline 12 & $<6$ & MTX & partial regression & - & - & 100 & $\mathrm{~F}$ \\
\hline 13 & 12 & MTX, GKS & - & 5 & - & 150 & LIP \\
\hline 14 & $<6$ & $\mathrm{CHQ}, \mathrm{GKS}$ & stabile & - & 100 & - & N \\
\hline 15 & 12 & $\mathrm{HQ}$ & progression & 5 & 150 & - & $N / F$ \\
\hline 16 & 21 & $\mathrm{CHQ}$ & - & 10 & - & 50 & $\mathrm{GGO} / \mathrm{ML}$ \\
\hline 17 & $<6$ & $\mathrm{CHQ}$ & - & - & - & 150 & $\mathrm{~F}$ \\
\hline 18 & $<6$ & $n$ dgn & - & 5 & - & - & $\mathrm{F}$ \\
\hline 19 & $<6$ & GKS & - & 15 & 150 & - & LIP/ ML \\
\hline 20 & $<6$ & ndgn & & 5 & - & - & $\mathrm{F}$ \\
\hline
\end{tabular}

$\mathrm{N}$ - nodules; F - pulmonary fibrosis (in this, GGO - ground-glass opacity image); LIP - lymphocytic interstitial pneumonia; ML - mediastinal lymphadenopathy; GKS - corticosteroids; MTX - methotrexate; HQ - hydroxychloroquine; CHQ - chloroquine; $n$ dgn - new diagnosis; chloroquine at a dose of $250 \mathrm{mg}$ per day or hydroxychloroquine at a dose of $200 \mathrm{mg}$ per day were administered in the treatment of all patients except one, number 19; cyclophosphamide at a dose of $800 \mathrm{mg}$ per month was administered intravenously in the treatment of patient number 2.

terstitial changes) indicating the need for HRCT scan. The chest HRCT scan in 30 patients revealed lung tissue changes in the progress of pSS in 20 of 30 patients (66\%), which made up $29 \%$ of all the examined patients (of 68). The discovered changes were: nodes (30\%), emphysema (40\%), fibrosis (65\%), lymphocytic interstitial pneumonia (10\%) and enlarged mediastinal lymph nodes (35\%). Emphysema changes have never exemplified a singular pathology and they have always involved the co-occurrence of nodules and pulmonary fibrosis. The mean age of patients diagnosed with chest changes seen on HRCT scan was 52 years. No correlation was found between the occurrence of HRCT changes and the age of the patients $(p=0.8)$, CRP concentration $(p=0.3)$, increased CRP concentration CRP $>5 \mathrm{mg} / 1(\mathrm{p}=0.1), \operatorname{ESR}(\mathrm{p}=0.2)$, abnormal ESR value - ESR > $20 \mathrm{~mm} / \mathrm{h}(\mathrm{p}=0.9)$, intensity of infiltration in focus score $(\mathrm{p}=0.8)$, number of leucocytes $(p=0.7)$, leucopenia $<4 \times 10 \% 9 / \mathrm{L}(\mathrm{p}=0.5), \mathrm{RF}$ value $(\mathrm{p}=0.3)$, gamma globulin value $(\mathrm{p}=0.5)$, intensity of eye dryness $(\mathrm{p}=0.6)$ or intensity of oral cavity dryness $(\mathrm{p}=0.3)$. Additionally, no correlation was found between more frequent occurrence of the antibodies anti-SSA, anti-SSB or anti-Ro52 and HRCT changes ( $\mathrm{p}=0.3$; 0.07; 0.4). According to the clinical data, HRCT changes occurred more often only in patients suffering from peripheral arthritis $(\mathrm{p}<0.01)$. The characteristics of all patients with pSS are presented in Table 2.

Treatment of lung changes and its effectiveness: $76 \%$ of 68 patients used chloroquine $(250 \mathrm{mg} /$ day or hydroxychloroquine $(200 \mathrm{mg} /$ day, $7 \%$ azathioprine (mean 
Table 2. The characteristics of all patients with pSS

\begin{tabular}{|c|c|c|c|}
\hline $\begin{array}{l}\text { Patients with pSS } \\
\text { all study groups }\end{array}$ & $\begin{array}{l}\text { With } \\
\text { changes } \\
\text { in chest } \\
\text { HRCT }\end{array}$ & $\begin{array}{l}\text { Without } \\
\text { changes } \\
\text { in chest } \\
\text { HRCT }\end{array}$ & $\mathrm{p}$-value \\
\hline Number of patients 68 & 20 & 10 & - \\
\hline Age 51 (19-80) years (min-max) & $52(31-72)$ & $\begin{array}{c}48 \\
(27-64)\end{array}$ & 0.78 \\
\hline $\mathrm{CRP}(\mathrm{mg} / \mathrm{L}) 2.33$ & 2.85 & 1.64 & 0.37 \\
\hline ESR $(\mathrm{mm} / \mathrm{h}) 26$ & 37 & 39 & 0.24 \\
\hline$\gamma$-globulin (g/dL) 1.4 & 1.7 & 1.5 & 0.50 \\
\hline $\mathrm{RF}(\mathrm{IU} / \mathrm{mL}) 92$ & 66 & 55 & 0.37 \\
\hline Focus score (0-4 score) 2 & 2 & 2 & 0.87 \\
\hline \multicolumn{4}{|c|}{ ESSPRI (cm): } \\
\hline eye dryness 4.2 & 4.9 & 4.3 & 0.64 \\
\hline oral cavity dryness 4.4 & 4.7 & 6.1 & 0.29 \\
\hline leucopenia <4000/u (n) 29 & 6 & 4 & 0.57 \\
\hline \multicolumn{4}{|c|}{ Clinical signs (number of patients): } \\
\hline skin changes 23 & 6 & 3 & 1.0 \\
\hline fatigue 28 & 15 & 8 & 0.27 \\
\hline arthralgia 48 & 15 & 9 & 0.14 \\
\hline salivary gland enlargement 33 & 10 & 7 & 0.29 \\
\hline arthritis 22 & 15 & 1 & $<0.001$ \\
\hline Raynaud syndrome 1 & 1 & 0 & 0.47 \\
\hline peripheral neuropathy 8 & 3 & 2 & 0.72 \\
\hline lymphadenopathy 15 & 6 & 6 & 0.11 \\
\hline
\end{tabular}

CRP - C-reactive protein; ESR - erythrocyte sedimentation rate; $\gamma$-globulin - value of gamma globulins marked in electrophoresis of proteins; RF - rheumatoid factor; ESSPRI - EULAR Sjögren's Syndrome Patient Reported Index Scale; (n) - number of patients.

$125 \mathrm{mg} /$ day), 20\% methotrexate (mean $16.5 \mathrm{mg} /$ week), $4 \%$ ciclosporin (mean $145 \mathrm{mg} /$ day) and $41 \%$ prednisolone (mean $6 \mathrm{mg} /$ day).

Chloroquine at a dose of $250 \mathrm{mg}$ per day or hydroxychloroquine at a dose of $200 \mathrm{mg}$ per day were administered in the treatment of all patients except one where ophthalmic contraindications made such therapy impossible. The details of the pharmacotherapy are presented in Table 1. Additionally, cyclophosphamide at a dose of $800 \mathrm{mg}$ per month was administered intravenously in the treatment of one patient (number 2) due to vasculitis manifested by palpable purpura and ulcers of the lower extremities. There was no correlation between treatment in all 68 patients and the indication to do chest HRCT ( $\mathrm{p}=0.7$, Student's t-test).

\section{Discussion}

T-lymphocyte infiltration localized in airways is leading to the epithelial cells damage and to the loss of their secretory function which is primarily manifested by coughing. Respiratory manifestations in pSS are heterogeneous and may include: dry cough, diffuse panbronchiolitis (DPB), bronchiectasis, nonspecific interstitial pneumonia (NSIP), idiopathic pulmonary fibrosis (IPF), cryptogenic organizing pneumonia (COP), lung cysts, nodular opacities, follicular bronchiolitis, lymphoid interstitial pneumonia (LIP), pseudolymphoma, lymphomatoid granulomatosis, lymphoma (usually of mucosaassociated lymphoid tissue type-MALT), pulmonary amyloidosis, pulmonary hypertension and pleural involvement. ${ }^{11,12}$ The mediastinal manifestations of pSS include lymphadenopathy, thymic lymphoid hyperplasia, multilocular thymic cysts and, rarely, MALT lymphoma. ${ }^{11,12}$ Such a wide range of manifestations may lead to significant diagnostic and therapeutic difficulties. Occasionally, a histopathological assessment of lung biopsy is needed. In HRCT scans, bronchial wall thickening (8-68\%), nodules (6-29\%), bronchiectasis (5-46\%), air trapping (32\%) and ground-glass attenuation were most frequently observed..$^{11-13}$

According to available publications, the prevalence of respiratory manifestations in pSS is estimated to be about $9-12 \%$ and clinical features are present in about $43-75 \%$ of patients when radiology imaging such as chest X-ray, HRCT or MRI are performed.

Papiris et al. found that cough occurred in $41 \%$ of patients with pSS. ${ }^{10}$ When HRCT was performed in all patients, the findings in the lungs were observed in up to $50 \%$ of patients; and when BAL was performed, the percentage increased to $55 \%$ in patients with pSS without clinical symptoms of lung involvement. The transformation risk of BAL changes into severe lung disease is unknown, therefore this test could not be routinely used in $\mathrm{pSS}$ with prognostic value. The clinical symptoms of lymphoma are frequently nonspecific and include dry cough or slowly increasing dyspnea. ${ }^{10}$ Similar to Papiris et al. in a comparable percentage ( $44 \%$ of patients), there were indications to perform chest HRCT. We found that the most common indication in $80 \%$ of patients was a persistent dry cough for at least 3 months and rarely dyspnea, reduced exercise tolerance due to dyspnea or sudden attacks of dry coughing. In the group of 30 patients, in case of 20 of them (66\%) changes on HRCT scans were found (29\% of patients from the whole group with pSS). Pulmonary fibrosis, emphysematous changes and mediastinal lymphadenopathy were the most common findings. In the recent Norwegian study, the percentage of lung involvement on HRCT scans in patients with pSS was similar to our findings ( $23 \%$ of patients out of 217 with pSS). ${ }^{4}$

Contrary to our research, most other studies reported the presence of predictive factors for pulmonary involve- 
ment in pSS (e.g., anti-SSB antibodies or hypergammaglobulinemia). ${ }^{14}$ Hyperglobulinemia was often observed in patients with pulmonary involvement in $\mathrm{pSS}$, which was not confirmed in our study. ${ }^{11}$ Unlike our results, the risk of airway involvement increased with male gender, older age at the time of diagnosis and in smokers. ${ }^{10}$

Factors such as older age and longer duration of pSS may be associated with bad prognosis but this was not confirmed in our study. Palma et al. found that the quality of life was lower in patients with pSS associated with pulmonary involvement compared to patients without airway changes, according to the Medical Outcomes Study 36-Item Short-Form Health Survey Physical Functioning $(\mathrm{p}=0.03)$. Additionally, in patients with pulmonary findings, increased mortality was observed after 10 years $(\mathrm{p}=0.002,17 \%$ vs $4.5 \%){ }^{4}$

Currently, the correlation between anti-SSA and antiSSB antibodies and airway involvement is not precisely explained and the findings from various studies contradict each other. ${ }^{14}$ Generally, the lung findings were more common when the anti-SSB antibodies were found than anti-SSA antibodies, which was not confirmed in our study, but the $\mathrm{p}$-value was higher in patients with anti-SSB antibodies than with anti-SSA antibodies in our study.

Many types of cytokines, such as IL-10, IL-6 and TGF- $\beta$, INF- $\gamma$, a unique chimera-type member of the $\beta$-galactoside-binding soluble lectin family galectin- 3 and lymphocytes Th1 and Th17 have been known to regulate the pathogenic process of ILD. ${ }^{15-17}$

Lin Yang et al. suggested the protective role of autoantibodies against interferon- $\gamma$, which significantly reduces the frequency of pulmonary fibrosis and concentration of C-reactive protein in patients with pSS. Autoantibodies against interferon- $\gamma$ may become a prognostic marker of pulmonary manifestations and have a close correlation with autoimmune inflammation in $\mathrm{pSS} .{ }^{18}$ In patients with pSS without prior ILD, the cumulative incidence of ILD in patients with pSS was $10 \%( \pm 3 \%) 1$ year after diagnosis of pSS and increased to $20 \%( \pm 4 \%) 5$ years after diagnosis of pSS. The development of lung disease in pSS was associated with poor survival. ${ }^{19}$ Thus, repeated pulmonary function tests and diagnostic radiology are necessary and should be the preferred methods to monitor pSS-specific organ involvement.

Pulmonary involvement in pSS may present in various forms and clinical manifestations that were included in the EULAR Sjögren's Syndrome Disease Activity Index (ESSDAI); this index includes clinical symptoms and objective tests such as persistent cough, shortness of breath on exercise, radiological or HRCT evidence of interstitial lung disease and abnormal lung function tests $\left(\mathrm{DL}_{\mathrm{co}}<70 \%\right.$, FVC $\left.<80 \%\right){ }^{5}$ Pulmonary domain weight stands at 5 points. Patients can accumulate 15 points in the case of the highly active pulmonary involvement. Five points in the ESSDAI index is considered to be a moderate activity of $\mathrm{pSS}$ and 14 points or more are cor- related with increased mortality. ${ }^{6}$ According to RamosCasals et al., the clinical domain with greatest activity during follow-up in comparison to the activity measured at diagnosis was the pulmonary part. At the beginning of the study, changes were observed only in $6 \%$ of patients and after 75 months the percentage increased to $15 \%$. The mean total ESSDAI score for this domain was low $(2-5)$. Older patients at the time of diagnosis ( $>70$ years) were less active during follow-up, but had a higher pulmonary activity score. ${ }^{7}$

Findings on the chest HRCT scan in our study were more common in patients with arthritis, but the group with these complications was relatively small.

For the time being, treatment of the pulmonary manifestations is undefined and is based on clinical experience. The explicit guideline (algorithm) does not exist yet. In patients with pSS and changes in the upper respiratory tract the most common symptoms are associated with dryness. Thus, muscarinic receptor agonists (pilocarpine and cevimeline) in nasal or throat sprays and humidifiers may be used in therapy. In pulmonary involvement, the treatment consists of immunosuppressive drugs such as hydroxychloroquine, azathioprine, cyclosporine and, in life-threatening cases, cyclophosphamide and corticosteroids. Isolated reports have suggested the benefits of using an oral cyclosporine in pSS patients with interstitial cystitis. In patients with active pSS, rituximab, belimumab and abatacept have also been used, but this treatment is uncommon due to its high cost, and questions relating to its usefulness in pSS still remain unanswered. ${ }^{21-24}$

In conclusion, pulmonary involvement in pSS is common and occurs in around 30\% of patients. This represents one of the most intriguing aspects of the disease. The main symptom is persistent dry cough that periodically wakes up patients at night. Radiological tests in daily clinical practice allow diagnosis of pulmonary findings, even if the changes are not very advanced. Additionally, they enable monitoring of pSS activity, because a factor or factors predisposing to the development of changes in the respiratory system have not been found. Changes in HRCT occur more frequently only in patients with peripheral arthritis.

\section{References}

1. Mavragani CP, Moutsopoulos HM. The geoepidemiology of Sjögren's syndrome. Autoimmun Rev. 2010;9:305-310.

2. Yazisiz V, Arslan G, Ozbudak IH, et al. Lung involvement in patients with primary Sjögren's syndrome: What are the predictors? Rheumatol Int. 2010;30:1317-1324.

3. Chen $\mathrm{MH}$, Chou HP, Lai CC, et al. Lung involvement in primary Sjögren's syndrome: Correlation between high-resolution computed tomography score and mortality. J Chin Med Assoc. 2014;77:75-82.

4. Palm O, Garen T, Berge Enger T, et al. Clinical pulmonary involvement in primary Sjögren's syndrome: Prevalence, quality of life and mortality - a retrospective study based on registry data. Rheumatol. 2013;52:173-179.

5. Seror R, Ravaud P, Bowman SJ, et al. EULAR Sjögren's syndrome disease activity index: Development of a consensus systemic dis- 
ease activity index for primary Sjögren's syndrome. Ann Rheum Dis. 2010;69:1103-1109.

6. Seror R, Bootsma $H$, Saraux A, et al. Defining disease activity states and clinically meaningful improvement in primary Sjögren's syndrome with EULAR primary Sjögren's syndrome disease activity (ESSDAI) and patient-reported indexes (ESSPRI). Ann Rheum Dis. doi: 10.1136/annrheumdis-2014-206008.

7. Ramos-Casals M, Brito-Zero'n P, Solans R, et al. Systemic involvement in primary Sjogren's syndrome evaluated by the EULAR-SS disease activity index: Analysis of 921 Spanish patients. Rheumatology. 2014;53:321-331.

8. Vitali $C$, Bombardieri $S$, Jonsson $S$, et al. Classification criteria for Sjögren's syndrome: A revised version of the European criteria proposed by the American-European Consensus Group. Ann Rheum Dis. 2002;61:554-558.

9. Meiners PM, Arends S, Brouwer E, Spijkervet FK, Vissink A, Bootsma H. Responsiveness of disease activity indices ESSPRI and ESSDAl in patients with primary Sjögren's syndrome treated with rituximab. Ann Rheum Dis. 2012;71:1297-1302.

10. Papiris SA, Maniati M, Constantopoulos SH, Roussos C, Moutsopoulos HM, Skopouli FN. Lung involvement in primary Sjögren's syndrome is mainly related to the small airway disease. Ann Rheum Dis. 1999;58:61-64.

11. Hatron PY, Tillie-Leblond I, Launay D, Hachulla E, Fauchais AL, Wallaert B. Pulmonary manifestations of Sjögren's syndrome. Presse Med. 2011;40:49-64.

12. Egashira R, Kondo T, Hirai T, et al. CT findings of thoracic manifestations of primary Sjögren syndrome: Radiologic-pathologic correlation. RadioGraphics. 2013;33:1933-1949.

13. Bellido-Casado J, Plaza V, Díaz C, et al. Bronchial inflammation, respiratory symptoms and lung function in primary Sjögren's syndrome. Arch Bronconeumol. 2011;47:330-334.

14. Yazisiz V, Arslan G, Ozbudak IH, et al. Lung involvement in patients with primary Sjögren's syndrome: What are the predictors? Rheumatol Int. 2010;30:1317-1324.

15. Fox RI, Kang H, Ando D, Abrams J, Pisa E. Cytokine mRNA expression in salivary gland biopsies of Sjogren's syndrome. J Immunol. 1994;152:5532-5539.

16. Moriyama M, Hayashida JN, Toyoshima T, et al. Cytokine/chemokine profiles contribute to understanding the pathogenesis and diagnosis of primary Sjögren's syndrome. Clin Exp Immunol. 2012;169:17-26.

17. Zhang R, Sun T, Song L, Zuo D, Xiao W. Increased levels of serum galectin-3 in patients with primary Sjögren's syndrome: Associated with interstitial lung disease. Cytokine. 2014;69:289-293.

18. Yang L, Bai L, Wei F, et al. Autoantibodies against interferon$Y$ reduce the frequency of pulmonary fibrosis and concentration of C-reactive protein in patients with primary Sjögren's syndrome. Mod Rheumatol. 2014:1439-7595.

19. Nannini C, Jebakumar AJ, Crowson CS, Ryu JH, Matteson EL. Primary Sjögren's syndrome 1976-2005 and associated interstitial lung disease: A population-based study of incidence and mortality. BMJ. 2013;3:e003569.

20. Deheinzelin D, Capelozzi VL, Kairalla RA, Barbas Filho JV, Saldiva $\mathrm{PH}$, de Carvalho CR. Interstitial lung disease in primary Sjögren's syndrome. Clinical-pathological evaluation and response to treatment. Am J Respir Crit Care Med. 1996;154:794-799.

21. Ogasawara H, Sekiya M, Murashima A, et al. Very low-dose cyclosporine treatment of steroid-resistant interstitial pneumonitis associated with Sjoögren's syndrome. Clin Rheumatol. 1998;17:160-162.

22. Emmungil H, Kalfa M, Zihni FY, et al. Interstitial cystitis: A rare manifestation of primary Sjogren's syndrome, successfully treated with low dose cyclosporine. Rheumatol Int. 2012;32:1215-1218.

23. Brito-Zero'n P, Siso'-Almirall A, Bove A, Kostov BA, Ramos-Casals M. Primary Sjögren syndrome: An update on current pharmacotherapy options and future directions. Expert Opin Pharmacother. 2013;14:279-289.

24. Zhan L, Mo H, Zhu M. Effect of cyclophosphamide on cytokines in patients with primary Sjögren's syndrome-associated interstitial lung disease in South China. Rheumatol Int. 2013;33:1403-1407. 